\title{
EVOLUÇÃO DO MARCO LEGAL DO LEITE CRU REFRIGERADO NO BRASIL
}

\section{Evolution of the legal framework of refrigerated raw milk in Brazil}

\author{
Luiz Paulo de Lima ${ }^{1 *}$, Gustavo Bastos Braga², Ronaldo Perez ${ }^{2}$, Luís Augusto Nero², \\ Antônio Fernandes de Carvalho ${ }^{2}$
}

\section{RESUMO}

Este manuscrito apresenta uma revisão da evolução do marco legal da produção de leite cru refrigerado no Brasil, desde a implementação do Programa Nacional de Melhoria de Qualidade do Leite - PNMQL, até os dias atuais. Após o início dos trabalhos do PNMQL, em 2002, foi criada a Rede Brasileira de Laboratórios da Qualidade do Leite - RBQL e aprovado o Regulamento Técnico de Produção, Identidade e Qualidade do Leite Cru Refrigerado. Desde então, tem sido observada uma evolução gradativa das normas referentes à produção de leite cru. Esta evolução vem sendo balizada por normas referentes à obtenção, conservação, transporte e padrões de qualidade do leite cru refrigerado. Contudo, dados oficiais sobre a qualidade do leite cru refrigerado produzido pelos produtores brasileiros não estão disponíveis. Além disso, são poucos os estudos de caso longitudinais que investigaram esta temática, após a implementação do PNMQL. Logo, ainda não está claro se a qualidade do leite produzido no campo tem efetivamente melhorado. Também, é preciso elucidar qual parcela de uma eventual melhoria da qualidade do leite cru refrigerado é proveniente das ações do PNMQL, e qual é proveniente da exclusão de pequenos produtores. O processo de melhoria da qualidade do leite cru refrigerado depende da atuação de todos os elos que compõem a sua cadeia produtiva produtores, indústria e governo. O governo deve regulamentar e fiscalizar, a indústria deve dar suporte aos produtores para que as metas sejam atingidas, e, finalmente, os produtores precisam atuar como parte interessada na melhoria da qualidade do leite.

Palavras-chave: laticínio, legislação, Programa Nacional de Melhoria de Qualidade do Leite.

1 Instituto Federal de Educação, Ciência e Tecnologia de Santa Catarina, Av. Expedicionários, 2150,Campo da Água Verde, 89466-312, Canoinhas, SC, Brasil. E-mail: luiz.paulo@ifsc.edu.br

2 Universidade Federal de Viçosa, Viçosa, MG, Brasil.

* Autor para correspondência 


\begin{abstract}
This manuscript presents a review of the evolution of the legal framework for the production of refrigerated raw milk in Brazil, from the implementation of the National Program for the Improvement of Milk Quality - PNMQL, to the present day. After the beginning of the work of the PNMQL, in 2002, the Brazilian Network of Milk Quality Laboratories - RBQL was created and the Technical Regulation for Production, Identity, and Quality of Refrigerated Raw Milk was approved. Since then, there has been a gradual evolution in the standards regarding the production of raw milk. This evolution has been guided by rules concerning the obtaining, conservation, transport, and quality standards of refrigerated raw milk. However, official data on the quality of refrigerated raw milk produced by Brazilian producers are not available. In addition, there are few longitudinal case studies that have investigated this issue, after the implementation of PNMQL. Therefore, it is still unclear whether the quality of milk produced in the field has actually improved. Also, it is necessary to clarify which portion of an eventual improvement in the quality of refrigerated raw milk comes from the actions of the PNMQL, and which comes from the exclusion of small producers. The process of improving the quality of refrigerated raw milk depends on the performance of all the links that make up the production chain - producers, industry, and government. The government must regulate and inspect, the industry must support producers so that the goals are achieved, and, finally, producers must act as an interested part in improving the milk quality.
\end{abstract}

Keywords: dairy, legislation, National Program for the Improvement of Milk Quality .

\section{INTRODUÇÃO}

O Brasil figura entre os cinco maiores produtores mundiais de leite desde a década de 1990 (FAO, 2020). Contudo, a produção brasileira é considerada pouco competitiva, quando comparada à produção dos principais países exportadores. Não obstante, o país vem se caracterizando muito mais como um importador de leite e derivados lácteos do que um exportador. De acordo com dados do Ministério da Indústria, Comércio Exterior e Serviços (BRASIL, 2020), desde 2008, a balança comercial de lácteos não apresenta um saldo positivo. Entre os motivos para tal, destacam-se a baixa qualidade do leite (FAGUNDES, 2006; CASSOLI; MACHADO, 2016) e a baixa produtividade de grande parte do rebanho leiteiro (SOUTO et al., 2009; REZENDE et al., 2012).
Para fazer frente a este cenário e, consequentemente, fortalecer a pecuária leiteira do País, em 1996, deu-se início à elaboração do Programa Nacional de Melhoria de Qualidade do Leite (PNMQL) em uma parceria estabelecida entre o Ministério da Agricultura, Pecuária e Abastecimento (MAPA), representantes da academia, de órgãos de pesquisa como a Empresa Brasileira de Pesquisa Agropecuária (EMBRAPA) e as associações de classe que representavam as indústrias. O PNMQL foi implementado pelo Departamento de Inspeção de Produtos de Origem Animal (DIPOA), pertencente ao MAPA. Desde então, a qualidade do leite cru produzido no Brasil tem sido analisada pela Rede Brasileira de Laboratórios da Qualidade do Leite (RBQL), conforme preconizado pela Instrução Normativa $\mathrm{n}^{\mathrm{o}} 37$ (IN-37) de 18 de abril de 2002 (BRASIL, 2002a). Atualmente, a 
RBQL é composta por 11 laboratórios oficiais, distribuídos em sete Estados (CBQL, 2020), responsáveis por analisar o leite formal (aquele inspecionado pela fiscalização sanitária) captado nas diversas regiões do País.

Inicialmente, os parâmetros de qualidade do leite cru refrigerado a serem cumpridos pelos produtores foram estabelecidos por meio da Instrução Normativa $\mathrm{n}^{\circ} 51$ (IN-51) de 18 de setembro de 2002 (BRASIL, 2002b), e, posteriormente, por suas revisões (BRASIL, 2009; 2011a; 2011b; 2016; 2018a; 2018b; 2018c; 2019a; 2019b). Entre alterações de padrões de qualidade, atualização dos prazos para o seu cumprimento, entre outras, foram muitas as transformações que a legislação pertinente à qualidade do leite cru refrigerado passou. Assim, o presente manuscrito tem como objetivo apresentar uma revisão da evolução do marco legal do leite cru refrigerado no Brasil, a partir da implementação do PNMQL.

\section{REFERENCIAL TEÓRICO}

Após debates com produtores, industriais, consumidores, vigilância sanitária e outras instituições públicas e privadas (PINTO, 2008), em maio de 1998, por meio da Portaria n ${ }^{\circ} 166$ (BRASIL, 1998), foi criado um grupo de trabalho para analisar e propor um programa de medidas visando o aumento da competitividade e a modernização do setor lácteo brasileiro. Como resultado dos trabalhos realizados, em dezembro de 1999, foi publicada a Portaria no 56 (BRASIL, 1999), abrindo para consulta pública o Regulamento Técnico de Produção, Identidade e Qualidade do Leite. Este regulamento trouxe regras para os diversos tipos de leite produzidos no Brasil. A consulta ficou aberta por 90 dias e, em função da demanda de entidades relacionadas aos pequenos produtores, reaberta em abril de 2002.

Ainda em abril de 2002, por meio da IN-37, foi criada a RBQL (BRASIL, 2002a). A RBQL é composta por laboratórios credenciados pelo Governo, a receber as amostras de leite cru provenientes de todos os produtores rurais que fornecem leite para os laticínios brasileiros (MILINSKI; VENTURA, 2010; CBQL, 2020). Dessa forma, a RBQL contribuiu para a padronização das análises, assegurando a credibilidade dos dados gerados, permitindo o mapeamento da qualidade do leite produzido nas diferentes regiões e o acompanhamento do histórico de seus indicadores de qualidade.

Posteriormente, em setembro de 2002, foi publicada a IN-51 (BRASIL, 2002b), com o objetivo de aprovar os Regulamentos Técnicos de Produção, Identidade e Qualidade dos Leites tipo A, tipo B e tipo C, além dos Regulamentos Técnicos de Identidade e Qualidade do Leite Pasteurizado e do Leite Cru Refrigerado, e do Regulamento Técnico da Coleta de Leite Cru Refrigerado e seu Transporte a Granel. Dessa forma, com relação aos Regulamentos Técnicos de Identidade e Qualidade do Leite Cru Refrigerado, e do Regulamento Técnico da Coleta de Leite Cru Refrigerado e seu Transporte a Granel, a IN-51 substituiu o Regulamento de Inspeção Industrial de Produtos de Origem Animal RIISPOA, de 1952 (BRASIL, 1952).

No que se refere ao leite cru refrigerado, a IN-51 estabeleceu a implementação de melhorias gradativas dos padrões de qualidade do leite produzido no campo, a partir do estabelecimento de indicadores de qualidade mais rigorosos ao longo dos anos, e regulamentou limites específicos para indicadores de qualidade físico-química, contagem de células somáticas (CCS) e contagem bacteriana total (CBT). Com relação ao planejamento de melhoria dos padrões de qualidade do leite cru refrigerado, cabe ressaltar que foram previstos dois cronogramas distintos para as diferentes regiões brasileiras. Para as regiões Sul, 
Sudeste e Centro-Oeste, por exemplo, a IN-51 previu o início da implementação da primeira fase (máximo de $1,0 \times 10^{6} \mathrm{UFC} / \mathrm{mL}$ para CBT e $1,0 \times 10^{6} \mathrm{CS} / \mathrm{mL}$ para $\mathrm{CCS}$ ) a partir de julho de 2005, enquanto que para as regiões Norte e Nordeste, a implementação da mesma fase se daria somente a partir de julho de 2007 (BRASIL, 2002b). A existência de prazos diferentes para a entrada em vigor dos padrões de CCS e CBT esteve embasada no pressuposto de que havia uma considerável diferença na qualidade do leite produzido nas regiões brasileiras. De acordo com Milinski e Ventura (2010), esta medida está em consonância com as diferenças econômicas e sociais existentes entre essas regiões.

O PNMQL, com a aprovação da IN-51, também buscou contribuir com a melhoria da qualidade do leite cru no Brasil por meio: (i) da obrigatoriedade do seu transporte a granel (embora a IN-51 ainda tenha admitido o transporte do leite em latões ou tarros e em temperatura ambiente para algumas condições específicas, como a entrega do leite no estabelecimento processador até duas horas após a conclusão da ordenha); (ii) da obrigatoriedade de refrigeração do leite na propriedade e no seu transporte à granel; (iii) da obrigatoriedade de análise oficial mensal do leite de todos os produtores que são fornecedores de leite para laticínios sob inspeção do Serviço de Inspeção Federal (SIF); e, (iv) do cadastramento dos produtores no Sistema de Informações Gerenciais do Serviço de Inspeção Federal (SIGSIF) (BRASIL, 2002b). Essas ações têm como foco a manutenção da cadeia do frio desde a ordenha até o laticínio; a identificação de falhas na origem, permitindo a correção diretamente com o produtor; e o acompanhamento da evolução da qualidade do leite produzido; além do estabelecimento de parâmetros de referência para a qualidade do leite cru refrigerado.

Em julho de 2009, dando continuidade às ações do PNMQL, foi publicada a Instrução Normativa $\mathrm{n}^{\circ} 22$ (IN-22) de 07 de julho de 2009. A IN-22 tem como objetivo atualizar as normas técnicas para utilização de tanques comunitários, visando à conservação da qualidade do leite cru, proveniente de diferentes propriedades rurais (BRASIL, 2009). Entre as normas estabelecidas para os tanques comunitários tem-se: (i) a existência de um responsável pela recepção do leite; (ii) a obrigatoriedade de cadastro do titular e dos demais produtores do tanque no SIGSIF; (iii) a proibição do recebimento de leite previamente refrigerado; e (iv) a instalação do tanque em local estratégico e adequado, provido de paredes, cobertura, pavimentação, iluminação, ventilação, condições de acesso apropriadas, ponto de água corrente e local próprio para higienização das mãos, latões e demais utensílios. Além disso, ficou estabelecido que o estabelecimento industrial seria responsável por capacitar e auditar periodicamente o titular e o responsável pela recepção, com relação à higienização dos equipamentos, à seleção e ao transporte higiênico do leite (BRASIL, 2009).

Posteriormente, em junho de 2011, por meio da Instrução Normativa $n^{\circ} 32$ (IN-32) de 30 de junho de 2011, foi instituído um Grupo de Trabalho com o objetivo de estabelecer novas diretrizes para o PNMQL (BRASIL, 2011a). Adicionalmente, em função de pedidos de representantes do setor produtivo, a IN-32 prorrogou por seis meses a implementação dos novos padrões de CCS e CBT para o leite cru refrigerado proveniente das regiões Sul, Sudeste e Centro-Oeste. À época, considerouse que a implementação dos novos padrões poderia levar à exclusão de um grande número de produtores (MILANI et al., 2016).

Em seguida, em dezembro de 2011, foi publicada a Instrução Normativa $\mathrm{n}^{\circ}$ 62 (IN-62) de 29 de dezembro de 2011 (BRASIL, 2011b). No que diz respeito ao Regulamento de Leite Cru Refrigerado, 
ficou estabelecida: (i) a disponibilização dos resultados das análises para o MAPA, para os estabelecimentos industriais e para os produtores; (ii) a obrigatoriedade do uso de tanques de refrigeração por expansão direta - até este momento ainda era permitido o uso de tanques de imersão; (iii) a obrigatoriedade do envio de amostras individualizadas, mesmo quando provenientes de tanques comunitários; entre outros. Além disso, a IN-62 formalizou a remuneração do produtor baseada na qualidade do leite, desde que estabelecida mediante acordo setorial específico (BRASIL, 2011b). Cabe ressaltar que, à época, o leite tipo $\mathrm{C}$ já havia sido extinto, conforme prazo estabelecido na IN-51 (BRASIL, 2002b).

O cronograma de implementação dos novos padrões de CCS e CBT para o leite cru refrigerado também foi atualizado: (i) para as regiões Sul, Sudeste e Centro-Oeste, os padrões previstos pela IN-51 (BRASIL, 2002 b) para entrar em vigor a partir de janeiro de 2012 (máximo de $1,0 \times 10^{5} \mathrm{UFC} / \mathrm{mL}$ para $\mathrm{CBT}$ e $4,0 \times 10^{5} \mathrm{CS} / \mathrm{mL}$ para $\mathrm{CCS}$ ) foram postergados por quatro anos e seis meses; ao passo que, (ii) para as regiões Norte e Nordeste, os mesmos padrões, que entrariam em vigor a partir de janeiro de 2013, tiveram seus prazos estendidos por cinco anos.

Além disso, foram inseridas duas novas fases ao cronograma de implementação dos padrões de qualidade do leite cru refrigerado. Estas novas fases contemplaram a implementação de padrões intermediários entre aqueles que estavam em vigência (máximo de $7,5 \times 10^{5} \mathrm{UFC} / \mathrm{mL}$ para CBT e $7,5 \times 10^{5} \mathrm{CS} / \mathrm{mL}$ para CCS) (BRASIL, 2011a) e aqueles que, a princípio, seriam implementados, a partir de janeiro de 2012, nas regiões Sul, Sudeste e Centro-Oeste, e de janeiro de 2013, nas regiões Norte e Nordeste (BRASIL, 2011b). Estes padrões intermediários, divididos em duas etapas, foram estabelecidos com previsão de vigorar: a partir de janeiro de 2012, para as regiões Sul, Sudeste e Centro-Oeste, e de janeiro de 2013, para as regiões Norte e Nordeste (máximo de $6,0 \times 10^{5} \mathrm{UFC} / \mathrm{mL}$ para CBT e $6,0 \times 10^{5} \mathrm{CS} / \mathrm{mL}$ para $\left.\mathrm{CCS}\right)$; e, posteriormente, a partir de julho de 2014, para as regiões Sul, Sudeste e Centro-Oeste, e de julho de 2015, para as regiões Norte e Nordeste (máximo de $3,0 \times 10^{5} \mathrm{UFC} / \mathrm{mL}$ para CBT e $5,0 \times 10^{5} \mathrm{CS} / \mathrm{mL}$ para CCS) (BRASIL, 2011b).

Posteriormente, em maio de 2016, a Instrução Normativa $\mathrm{n}^{\circ} 7$ (IN-7), de 03 de maio de 2016, atualizou o cronograma de implementação dos novos padrões de CCS e CBT. Os novos padrões (máximo de $1,0 \times 10^{5} \mathrm{UFC} / \mathrm{mL}$ para CBT e $4,0 \times 10^{5} \mathrm{CS} / \mathrm{mL}$ para CCS), previstos pela IN-62 (BRASIL, 2011b) para entrar em vigor a partir de julho de 2016, nas regiões Sul, Sudeste e Centro-Oeste, e julho de 2017, nas regiões Norte e Nordeste, foram prorrogados por dois anos. Dessa forma, estes padrões só passariam a vigorar a partir de julho de 2018, nas regiões Sul, Sudeste e Centro-Oeste, e de julho de 2019, nas regiões Norte e Nordeste (BRASIL, 2016).

Contudo, em junho de 2018 a Instrução Normativa $\mathrm{n}^{\circ} 31$ (IN-31), de 29 de junho de 2018, atualizou o cronograma de implementação dos novos padrões de CCS e CBT, para as regiões Sul, Sudeste e Centro-Oeste. Os padrões, anteriormente previstos para entrarem em vigor a partir de julho de 2018 (máximo de $1,0 \times 10^{5} \mathrm{UFC} / \mathrm{mL}$ para $\mathrm{CBT}$ e $4,0 \times 10^{5} \mathrm{CS} / \mathrm{mL}$ para $\mathrm{CCS}$ ), foram postergados para julho de 2019. Este novo prazo coincidiu com aquele estabelecido pela IN-7 para as regiões Norte e Nordeste. Dessa forma, a partir de julho de 2019, os produtores de leite cru refrigerado de todas as regiões do País deveriam atender aos mesmos padrões de qualidade (máximo de $1,0 \times 10^{5} \mathrm{UFC} / \mathrm{mL}$ para CBT e $4,0 \times 10^{5} \mathrm{CS} / \mathrm{mL}$ para CCS) (BRASIL, 2018a).

Todavia, em novembro de 2018, após consultas públicas realizadas entre abril e junho de 2018 (BRASIL, 2018d; 2018e), foram publicadas a Instrução Normativa $n^{\circ} 76$ (IN-76) 
e a Instrução Normativa $\mathrm{n}^{\mathrm{o}} 77$ (IN-77), ambas de 26 de novembro de 2018. A IN-76 aprovou novos Regulamentos Técnicos com o objetivo de fixar a Identidade e as Características de Qualidade que devem apresentar o Leite Cru Refrigerado, o Leite Pasteurizado e o Leite Pasteurizado tipo A (BRASIL, 2018b). No que se refere ao Leite Cru Refrigerado, a IN-76: (i) atualizou os padrões de qualidade físico-química (Tabela 1); (ii) estabeleceu limites máximos de temperatura do leite para o recebimento $\left(7^{\circ} \mathrm{C}\right)$, para a conservação e a expedição no posto de refrigeração, e para a conservação na usina de beneficiamento, ou fábrica de laticínios, antes da pasteurização $\left(4{ }^{\circ} \mathrm{C}\right)$; (iii) estabeleceu o limite máximo para a CBT do leite antes do seu processamento no estabelecimento beneficiador $\left(9,0 \times 10^{5} \mathrm{UFC} / \mathrm{mL}\right)$; (iv) exigiu a identificação, por meio de rotulagem, e a existência de boletim de análises do laboratório do estabelecimento expedidor, para o leite cru refrigerado proveniente de posto de refrigeração; e (v) fixou padrões para CCS e CBT (máximo de 3,0×10 $\mathrm{UFC} / \mathrm{mL}$ para CBT e $5,0 \times 10^{5} \mathrm{CS} / \mathrm{mL}$ para CCS) (BRASIL, 2018b). Dessa forma, desde a entrada em vigor da legislação, entre maio e junho de 2019, os valores máximos para CCS e CBT, até então em vigor pela IN-31 (BRASIL, 2018a), foram adotados como padrão, sem que houvesse diferenciação por região do País, nem novos padrões a serem cumpridos em prazos específicos. A Tabela 1 ilustra os novos padrões de qualidade físico-química do leite cru refrigerado, implementados pela IN-76 (BRASIL, 2018b), em comparação com aqueles que estavam em vigência anteriormente (BRASIL, 2002b; 2011b).

Por outro lado, a IN-77 estabeleceu os critérios e procedimentos para produção, acondicionamento, conservação, transporte, seleção e recepção do leite cru em estabelecimentos registrados no SIF (BRASIL, 2018c). Por meio desta, entre outros, ficou definido que as propriedades rurais devem: (i) utilizar sistema de préresfriamento e/ou tanque de expansão direta para a refrigeração do leite cru, e (ii) refrigerar o leite nos tanques a $4{ }^{\circ} \mathrm{C}$, em até 3 horas; enquanto os estabelecimentos devem: (i) receber o leite refrigerado em

Tabela 1 - Padrões de qualidade físico-química do leite cru refrigerado, estabelecidos pelas IN-51, IN-62 e IN-76

\begin{tabular}{ccccc}
\hline Variável & IN-51 & IN-62 & IN-76 & Unidade \\
\hline Extrato seco & $\geq 8,4$ & $\geq 8,4$ & $\geq 8,4$ & $\mathrm{~g} / 100 \mathrm{~g}$ \\
desengordurado & $*$ & $*$ & $\geq 11,4$ & $\mathrm{~g} / 100 \mathrm{~g}$ \\
Extrato seco total & $\geq 3,0$ & $\geq 3,0$ & $\geq 3,0$ & $\mathrm{~g} / 100 \mathrm{~g}$ \\
Gordura & $*$ & $*$ & $\geq 4,3$ & $\mathrm{~g} / 100 \mathrm{~g}$ \\
Lactose anidra & $\geq 2,9$ & $\geq 2,9$ & $\geq 2,9$ & $\mathrm{~g} / 100 \mathrm{~g}$ \\
Proteína total & 0,14 a 0,18 & 0,14 a 0,18 & 0,14 a 0,18 & $\mathrm{~g}$ ácido lático/ $100 \mathrm{~mL}$ \\
Acidez titulável & 1,028 a 1,034 & 1,028 a 1,034 & 1,028 a 1,034 & $\mathrm{~g} / \mathrm{mL}$ \\
Densidade relativa & $\geq 72$ & $\geq 72$ & $\geq 72$ & $\%$ \\
Estabilidade ao alizarol & $\leq-0,530$ & $-0,550$ a $-0,530$ & $-0,555$ a $-0,530$ & ${ }^{\circ} \mathrm{H}$ \\
Índice crioscópico & $(\leq-0,512)$ & $(-0,531 \mathrm{a}-0,512)$ & $(-0,536 \mathrm{a}-0,512)$ & $\left({ }^{\circ} \mathrm{C}\right)$ \\
\hline
\end{tabular}

* não informado.

Fonte: BRASIL (2002b; 2011b; 2018b). 
temperatura não superior a $7{ }^{\circ} \mathrm{C}$ (admitindose, excepcionalmente, o recebimento até $9{ }^{\circ} \mathrm{C}$ ), (ii) manter programa de autocontrole para qualificação dos fornecedores de leite, (iii) interromper a coleta de leite em propriedades que apresentarem, por três meses consecutivos, média geométrica (trimestral) fora do padrão estabelecido para CBT, e (iv) realizar, pelo menos uma vez por mês, análise da CBT do leite cru refrigerado estocado na indústria, em laboratório da RBQL. Com relação à interrupção da coleta de leite em propriedades com alta média geométrica para Contagem Padrão em Placas (CPP), por meio da própria IN-77, considera-se que o resultado de uma única nova amostra, analisada pela RBQL, dentro do padrão regulamentar é suficiente para a retomada da coleta (BRASIL, 2018c).

Por fim, em novembro de 2019, as Instruções Normativas $n^{0} 76$ e $n^{\circ} 77$ foram alteradas, respectivamente, pelas Instruções Normativas $\mathrm{n}^{\circ} 58$ - IN-58 e $\mathrm{n}^{\circ} 59$ - IN-59. A IN-58 previu que, "em caso de ausência de resultado mensal para composição da média geométrica trimestral, o resultado de cada mês subsequente substituirá a média geométrica até o restabelecimento da média geométrica trimestral calculada". Além disso, a IN-58 também alterou o plano de amostragem microbiológica estabelecido para avaliação da CPP do leite cru refrigerado antes do seu processamento no estabelecimento industrial (BRASIL, 2019a).

Já a IN-59 estabeleceu que a análise do leite de novos produtores deve ser realizada em laboratórios pertencentes à RBQL, e impôs que, antes do restabelecimento da coleta de leite, deve ser identificada a causa do desvio. Além disso, a IN-59 revogou a obrigatoriedade de os laticínios manterem programa de autocontrole de educação continuada dos produtores rurais, e estabeleceu a análise de CPP para o leite cru refrigerado antes do seu processamento
(BRASIL, 2019b). Anteriormente, a IN-77 previa que esta análise seria realizada para o leite cru refrigerado estocado (BRASIL, 2018c).

A consulta pública do Regulamento Técnico de Produção, Identidade e Qualidade do leite e, posteriormente, a publicação da IN-51, estabeleceram padrões de qualidade para o leite produzido no Brasil. Até então, o leite cru refrigerado não possuía um padrão de qualidade (BRASIL, 1952). Portanto, só a partir da publicação da IN-51 (BRASIL, 2002b) é que os produtores passaram a ter conhecimento dos requisitos de qualidade que o leite deve possuir, enquanto as indústrias passaram a ter critérios para recusar o recebimento de leite de baixa qualidade (MILINSKI; VENTURA, 2010).

Após a implantação da IN-51, acreditava-se que a cadeia do leite passaria por muitas transformações, num período relativamente curto - sete anos. De acordo com o cronograma inicialmente previsto na IN-51 (BRASIL, 2002b), a partir de julho de 2012, o leite produzido em todo o País atingiria um padrão de qualidade internacional (máximo de $1,0 \times 10^{5} \mathrm{UFC} / \mathrm{mL}$ para $\mathrm{CBT}$ e $4,0 \times 10^{5} \mathrm{CS} / \mathrm{mL}$ para CCS ). A União Europeia exige $1,0 \times 10^{5} \mathrm{UFC} / \mathrm{mL}$ e $4,0 \times 10^{5} \mathrm{CS} / \mathrm{mL}$ para CBT e CCS, respectivamente (EC, 2004),

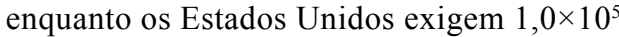
$\mathrm{UFC} / \mathrm{mL}$ e $7,5 \times 10^{5} \mathrm{CS} / \mathrm{mL}$ para CBT e CCS, respectivamente (FDA, 2017). No entanto, a qualidade do leite cru refrigerado parece não ter evoluído no ritmo esperado, o que levou a sucessivas revisões dos cronogramas de implementação de novos padrões de CBT e CCS (BRASIL, 2011a; 2016; 2018a).

Apesar disso, os padrões atualmente em vigor (máximo de $3,0 \times 10^{5} \mathrm{UFC} / \mathrm{mL}$ para $\mathrm{CBT}$ e $5,0 \times 10^{5} \mathrm{CS} / \mathrm{mL}$ para CCS) (BRASIL, 2018b) são muito mais rigorosos do que aqueles implementados na primeira fase do PNMQL (máximo de $1,0 \times 10^{6} \mathrm{UFC} / \mathrm{mL}$ para CBT e $1,0 \times 10^{6} \mathrm{CS} / \mathrm{mL}$ para CCS) (BRASIL, 2002b). 
A Figura 1 ilustra a evolução dos padrões de CBT e CCS que foram estabelecidos ao longo deste período. Em consonância com a evolução dos padrões estabelecidos, Ribas et al. (2016) verificaram tendência de redução do indicador de CBT de amostras de leite entregues no Laboratório da Qualidade do Leite da Associação Paranaense dos Criadores de Bovinos da Raça Holandesa, em Curitiba, PR. Os dados fazem referência ao período entre janeiro de 2012 e maio de 2014. Por outro lado, Lima et al. (2020) identificaram uma piora dos indicadores de qualidade do leite proveniente de produtores da Zona da Mata mineira. Os dados fazem referência ao período entre os anos de 2012 e 2018.

De acordo com o relatório Mapa da Qualidade do Leite, publicado pela Clínica do Leite, a média geométrica do leite cru analisado pelo laboratório aumentou entre os anos de 2006 e 2008. A partir de 2009 estes valores diminuíram continuamente até 2012, voltado a aumentar após 2013 (CASSOLI; MACHADO, 2016). Os dados são referentes a fornecedores de leite de indústrias processadores dos estados de Minas Gerais, São Paulo, Goiás, Paraná, Rio de Janeiro, Mato Grosso do Sul, Ceará e Bahia. Cabe ressaltar que, muitas vezes, os produtores não conseguem produzir leite em conformidade com os novos padrões de qualidade simplesmente por não seguirem as boas práticas de manejo (VELTHUIS; VAN ASSELDONK, 2011) e de ordenha (PANTOJA et al., 2009; LAMAS et al., 2015).

Estes exemplos reforçam os já esperados contrastes de qualidade do leite proveniente de diferentes regiões do país (MILINSKI; VENTURA, 2010). Soma-se a este fato a escassez de estudos de caso longitudinais e a ausência de dados oficiais sobre a qualidade do leite cru refrigerado produzido pelos produtores brasileiros. Logo, não é possível afirmar se a qualidade do leite cru refrigerado produzido no Brasil efetivamente melhorou ao longo deste período. Assim como não é possível mensurar a parcela de contribuição de cada uma das ações implementadas, ou das instruções normativas publicadas. Nem mesmo é possível isolar o efeito de milhares de pequenos produtores terem abandonado a atividade. Dados do Instituto Brasileiro de Geografia e Estatística (IBGE) contabilizam uma diminuição de 180 mil estabelecimentos agropecuários produtores de leite entre os censos agropecuários de 2006 e 2017 (IBGE, 2020a; 2020b).

Ainda assim, há uma grande diferença entre os padrões de qualidade inicialmente estabelecidos pela IN-51 (BRASIL, 2002b) e aqueles atualmente em vigor (BRASIL, 2018b). Certamente houve uma evolução do marco legal do leite cru refrigerado neste período. A Figura 2 ilustra uma linha do tempo das normas pertinentes ao marco legal do leite cru refrigerado, desde a implementação do PNMQL. Contudo, para que esta evolução possa se refletir na melhoria da qualidade do leite cru refrigerado produzido no Brasil, é preciso uma atuação conjunta de todos os elos de sua cadeia produtiva - produtores, indústria e governo.

O governo deu início a este processo, por meio do PNMQL. Consequentemente, contribuiu para a aprovação de legislações relacionadas ao estabelecimento de padrões de qualidade para o leite cru refrigerado e aos procedimentos a serem adotados pelos produtores, transportadores e indústria, desde a coleta até o beneficiamento do leite. Todavia, a contribuição dos órgãos governamentais deve passar não só pelo processo de revisão e atualização do marco regulatório do leite cru refrigerado, mas também incluir assistência técnica aos produtores, melhoria da infraestrutura no campo, intensificação da fiscalização, transparência dos dados de qualidade provenientes das análises oficiais, etc.

A indústria, por sua vez, precisa, entre outros, garantir a refrigeração do leite durante 

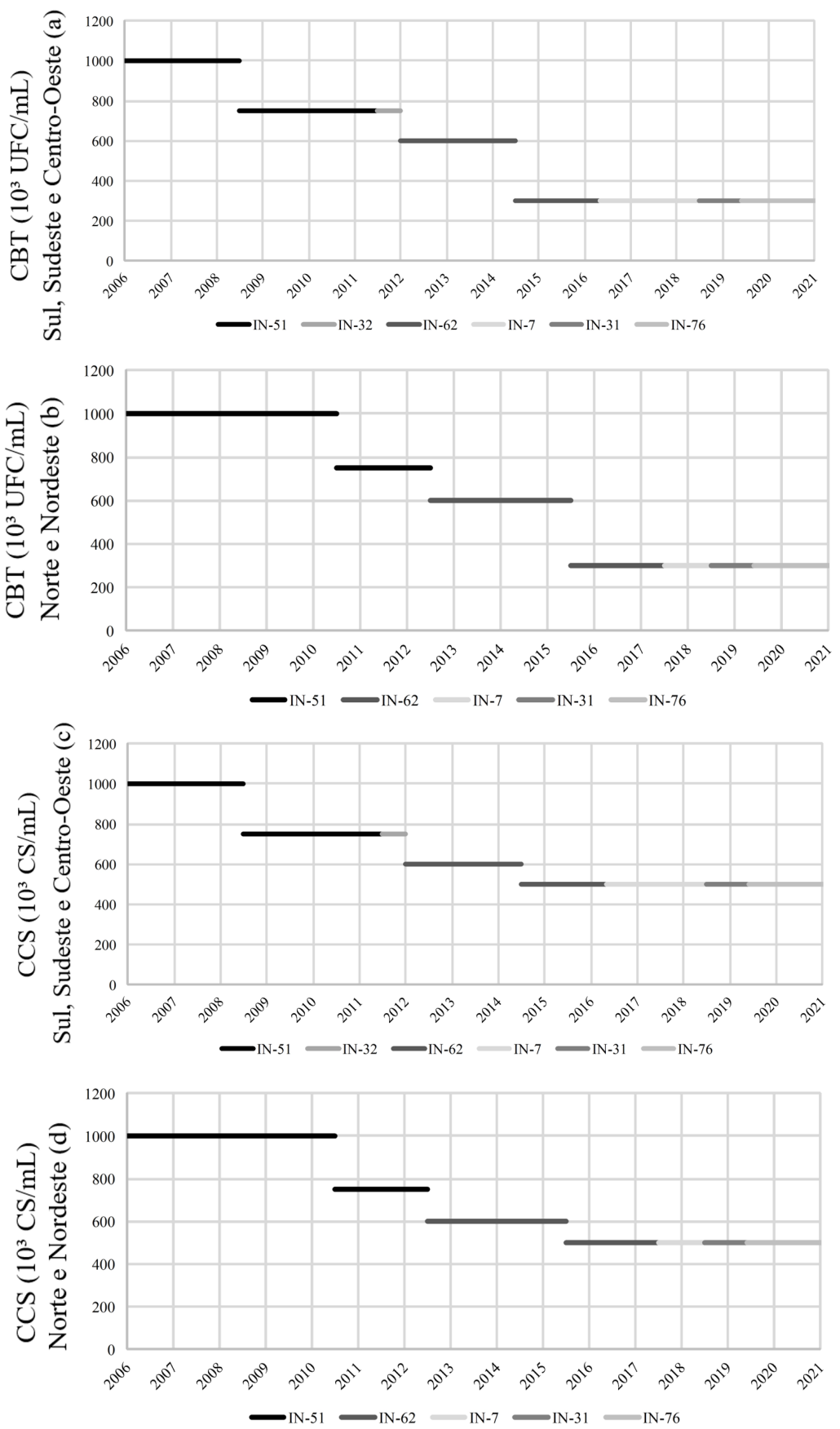

Figura 1 - Evolução dos padrões estabelecidos para o leite cru refrigerado. CBT para as regiões Sul, Sudeste e Centro-Oeste (a); CBT para as regiões Norte e Nordeste (b); CCS para as regiões Sul, Sudeste e Centro-Oeste (c); e, CCS para as regiões Norte e Nordeste (d) 
o seu transporte (BRASIL, 2002b; 2018b), a realização de análise oficial mensal do leite de todos os produtores (BRASIL, 2002b), a pesquisa diária de agentes inibidores de crescimento microbiano, a remuneração do produtor baseada na qualidade do leite (BRASIL, 2011b), a estocagem do leite em temperatura e contagem bacteriana adequadas (BRASIL, 2018b), além de dar suporte aos produtores para que estes padrões sejam atingidos.

Por fim, os produtores precisam reconhecer sua importância como base da cadeia e, assim, atuar como parte interessada na melhoria da qualidade do leite. Entre outros, os produtores devem assegurar a sanidade dos animais (BRASIL, 2011b), a obtenção do leite em condições higiênicas (BRASIL, 2002b; 2011b), e a sua refrigeração na propriedade (BRASIL, 2002b), por meio do uso de tanques de refrigeração por expansão direta (BRASIL, 2011b; 2018c).

Com relação aos entraves para que o leite cru refrigerado produzido no Brasil atinja o padrão de qualidade dos principais produtores mundiais, pode-se citar: assistência técnica (FLORES-MIYAMOTO et al., 2014), infraestrutura no campo (tanques de refrigeração, por exemplo) (CASTRO et al., 2016), pagamento pela qualidade do leite (NIGHTINGALE et al., 2008; BOTARO et al., 2013), oferta de crédito aos produtores (OLIVEIRA et al., 2011), condições de acesso às áreas rurais e conservação das estradas. Portanto, o processo de melhoria da qualidade do leite cru refrigerado produzido no Brasil

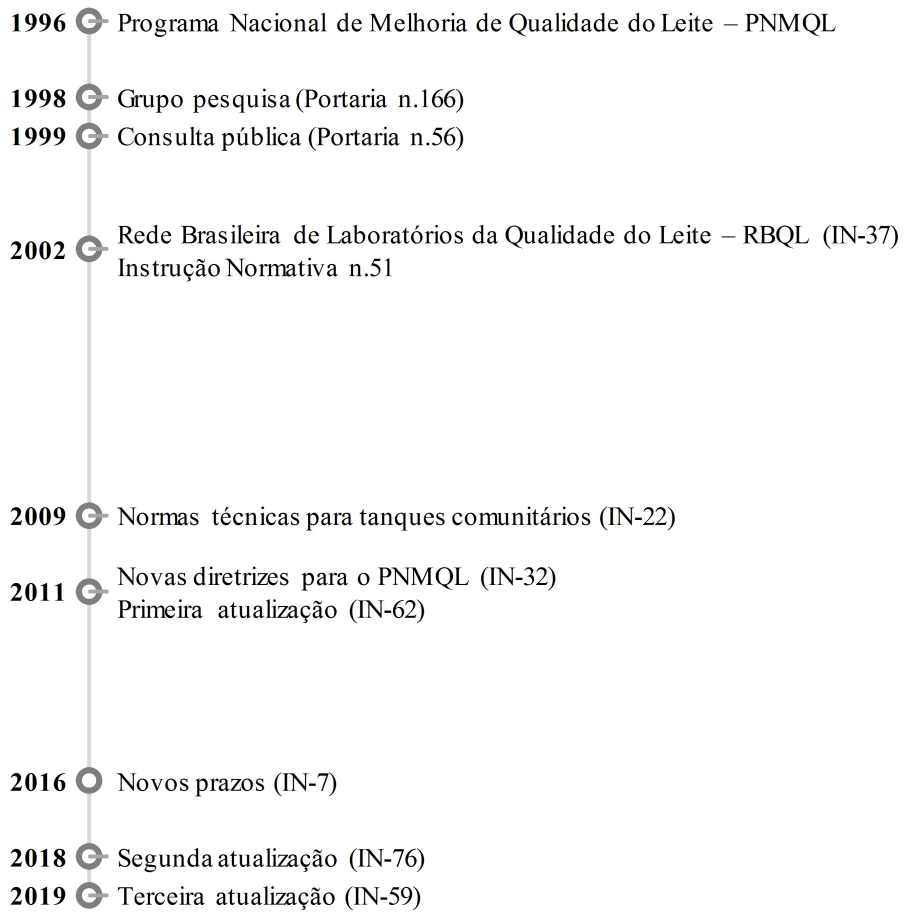

Figura 2 - Linha do tempo das normas pertinentes ao marco legal do leite cru refrigerado, desde a implementação do PNMQL 
depende da atuação de todos os elos que compõem a sua cadeia produtiva - produtores, indústria e governo.

\section{CONSIDERAÇÕES FINAIS}

Desde o início dos trabalhos do Programa Nacional de Melhoria de Qualidade do Leite e a implementação de padrões de qualidade por meio da Instrução Normativa $n^{0} 51$, houve uma evolução considerável das normas referentes à obtenção, conservação e transporte do leite, além dos seus próprios padrões de qualidade. Contudo, ainda não está claro se a qualidade do leite produzido no campo tem efetivamente melhorado. Além disso, também é preciso elucidar qual parcela de uma eventual melhoria da qualidade do leite cru refrigerado é proveniente das ações do PNMQL, e qual é proveniente da exclusão de pequenos produtores. O processo de melhoria da qualidade do leite cru refrigerado produzido no Brasil depende da atuação de todos os elos que compõem a sua cadeia produtiva - produtores, indústria e governo.

\section{REFERÊNCIAS}

BOTARO, B. G.; GAMEIRO, A. H.; SANTOS, M. V. Quality based payment program and milk quality. Scientia Agricola, v. 70 , n. 1, p. 21-26, 2013. DOI: 10.1590/ S0103-90162013000100004.

BRASIL. Decreto n ${ }^{\circ} 30.691$, de 29 de março de 1952. Aprova o novo Regulamento da Inspeção Industrial e Sanitária de Produtos de Origem Animal. Diário Oficial da República Federativa do Brasil: seção 1, Brasília, DF, n. 155 , p. $10.785,07$ jul. 1952.

BRASIL. Ministério da Agricultura e do Abastecimento. Portaria $\mathrm{n}^{\circ} 56$, de 07 de dezembro de 1999. Submete à Consulta Pública os Regulamentos Técnicos de
Produção, Identidade e Qualidade de leite tipo A; leite tipo B, leite tipo $\mathrm{C}$, leite cru resfriado, leite pasteurizado, leite de cabra e Coleta de leite cru resfriado e seu transporte a granel. Diário Oficial da República Federativa do Brasil: seção 1, Brasília, DF, n. 234, p. 34, 08 dez. 1999.

BRASIL. Ministério da Agricultura e do Abastecimento. Portaria $\mathrm{n}^{\circ} 166$, de 05 de maio de 1998. Cria grupo de trabalho para analisar e propor programa e medidas visando ao aumento da competitividade e à modernização do setor produtivo de leite e derivados no Brasil. Diário Oficial da República Federativa do Brasil: seção 1, Brasília, DF, n. 84, p. 42, 06 maio 1998.

BRASIL. Ministério da Agricultura, Pecuária e Abastecimento. Instrução Normativa $\mathrm{n}^{\circ} 7$, de 03 de maio de 2016. Altera a tabela 2 do item 3.1.3.1 do Anexo II da Instrução Normativa $n^{\circ}$ 62, de 29 de dezembro de 2011. Diário Oficial da União: seção 1, Brasília, DF, n. 84, p. 11, 04 maio 2016.

BRASIL. Ministério da Agricultura, Pecuária e Abastecimento. Instrução Normativa $n^{\circ}$ 22, de 07 de julho de 2009. Estabelece as normas técnicas para utilização de tanques comunitários visando à conservação da qualidade do leite cru, proveniente de diferentes propriedades rurais. Diário Oficial da União: seção 1, Brasília, DF, n. 128, p. 8, 08 jul. 2009.

BRASIL. Ministério da Agricultura, Pecuária e Abastecimento. Instrução Normativa $n^{\circ} 31$, de 29 de junho de 2018. Aprova o Regulamento Técnico de Produção, Identidade e Qualidade do leite tipo A, de leite cru refrigerado, de leite pasteurizado e o Regulamento Técnico da Coleta de Leite Cru Refrigerado e seu Transporte a Granel. Diário Oficial da União: seção 1, Brasília, DF, n. 125, p. 3, 02 jul 2018a. 
BRASIL. Ministério da Agricultura, Pecuária e Abastecimento. Instrução Normativa $n^{\circ} 32$, de 30 de junho de 2011. Prorroga por 6 meses a vigência dos prazos estabelecidos para a adoção de novos limites microbiológicos e de células somáticas, que entrariam em vigor a partir de $1^{\circ}$ de julho de 2011 para as regiões Sul, Sudeste e Centro-Oeste, e Institui Grupo de Trabalho com o objetivo de estabelecer novas diretrizes do Programa Nacional de Melhoria da Qualidade do Leite, bem como definir competências e compromissos de cada elo envolvido na cadeia produtiva do leite. Diário Oficial da União: seção 1, Brasília, DF, n. 125, p. 4, 01 jul. 2011a.

BRASIL. Ministério da Agricultura, Pecuária e Abastecimento. Instrução Normativa $n^{\circ}$ 37, de 18 de abril de 2002. Institui a Rede Brasileira de Laboratórios de Controle da Qualidade do Leite, com o objetivo de realizar análises laboratoriais para fiscalização de amostras de leite cru, recolhidas em propriedades rurais e em estabelecimentos de laticínios. Diário Oficial da União: seção 1, Brasília, DF, n. 75, p. 3, 19 abr. 2002a.

BRASIL. Ministério da Agricultura, Pecuária e Abastecimento. Instrução Normativa $n^{\circ} 51$, de 18 de setembro de 2002. Regulamentos técnicos de produção, identidade e qualidade do leite tipo A, do leite tipo B, do leite tipo C, do leite pasteurizado e do leite cru refrigerado e o Regulamento técnico da coleta de leite cru refrigerado e seu transporte a granel. Diário Oficial da União: seção 1, Brasília, DF, n. 183, p. 13, 20 set. 2002b.

BRASIL. Ministério da Agricultura, Pecuária e Abastecimento. Instrução Normativa $n^{\circ} 58$, de 06 de novembro de 2019. Altera a Instrução Normativa $\mathrm{n}^{\circ} 76$, de 26 de novembro de 2018 . Diário Oficial da União: seção 1, Brasília, DF, n. 216, p. 18, 07 nov. 2019a.

BRASIL. Ministério da Agricultura, Pecuária e Abastecimento. Instrução Normativa n ${ }^{\circ} 59$, de 06 de novembro de 2019. Altera a Instrução Normativa $\mathrm{n}^{\mathrm{0}} 77$, de 26 de novembro de 2018. Diário Oficial da União: seção 1, Brasília, DF, n. 216, p. 18, 07 nov. 2019b.

BRASIL. Ministério da Agricultura, Pecuária e Abastecimento. Instrução Normativa $n^{\circ}$ 62, de 29 de dezembro de 2011. Aprova o Regulamento Técnico de Produção, Identidade e Qualidade do Leite tipo A, o Regulamento Técnico de Identidade e Qualidade de Leite Cru Refrigerado, o Regulamento Técnico de Identidade e Qualidade de Leite Pasteurizado e o Regulamento Técnico da Coleta de Leite Cru Refrigerado e seu Transporte a Granel. Diário Oficial da União: seção 1, Brasília, DF, n. 251, p. 6, 30 dez 2011b.

BRASIL. Ministério da Agricultura, Pecuária e Abastecimento. Instrução Normativa $\mathrm{n}^{\mathrm{0}} 76$, de 26 de novembro de 2018. Regulamentos Técnicos que fixam a identidade e as características de qualidade que devem apresentar o leite cru refrigerado, o leite pasteurizado e o leite pasteurizado tipo A. Diário Oficial da União: seção 1, Brasília, DF, n. 230 , p. 9,30 nov. 2018 b.

BRASIL. Ministério da Agricultura, Pecuária e Abastecimento. Instrução Normativa $n^{\circ}$ 77, de 26 de novembro de 2018. Estabelece os critérios e procedimentos para a produção, acondicionamento, conservação, transporte, seleção e recepção do leite cru em estabelecimentos registrados no serviço de inspeção oficial. Diário Oficial da União: seção 1, Brasília, DF, n. 230, p. 10, 30 nov. 2018c.

BRASIL. Ministério da Agricultura, Pecuária e Abastecimento. Portaria $n^{\circ} 38$, de 19 de abril de 2018. Submete à Consulta Pública, pelo prazo de 60 dias, a contar da data da publicação desta Portaria, a proposta de Instrução Normativa, anexa, que estabelece os Regulamentos Técnicos que fixam a 
identidade e as características de qualidade que devem apresentar o leite cru refrigerado, o leite pasteurizado e o leite tipo A. Diário Oficial da União: seção 1, Brasília, DF, n. 80, p.17, 26 abr. $2018 \mathrm{~d}$.

BRASIL. Ministério da Agricultura, Pecuária e Abastecimento. Portaria $n^{\circ} 39$, de 19 de abril de 2018. Submete à Consulta Pública, pelo prazo de 60 dias, a contar da data da publicação desta Portaria, a proposta de Instrução Normativa, anexa, que estabelece os critérios e procedimentos para a produção, acondicionamento, conservação, transporte, seleção e recepção do leite cru em estabelecimentos registrados no serviço de inspeção oficial. Diário Oficial da União: seção 1, Brasília, DF, n. 80, p.18, 26 abr. 2018e.

BRASIL, Ministério da Indústria, Comércio Exterior e Serviços. Estatísticas de comércio exterior. Disponível em: http://www. mdic.gov.br/index.php/comercio-exterior/ estatisticas-de-comercio-exterior/serieshistoricas. Acesso em: 26 mar. 2020.

CASSOLI, L. D.; MACHADO, P. F. Mapa da Qualidade do Leite: CBT - Contagem Bacteriana Total. 1. ed. Piracicaba: Clínica do Leite - ESALQ/USP, 2016. 40 p. Disponível em: https://www.embrapa.br/ documents/1354377/39803784/CBT_Mapada-Qualidade Clin-Leite.pdf/ad95f20ae103-d244-c394-e9e25e90dbf9?version=1.0. Acesso em: 07 jun. 2020.

CASTRO, R. D. et al. Lactic acid microbiota identification in water, raw milk, endogenous starter culture, and fresh Minas artisanal cheese from the Campo das Vertentes region of Brazil during the dry and rainy seasons. Journal of Dairy Science, v. 99, n. 8, p. 60866096, 2016. DOI: 10.3168/jds.2015-10579.

CBQL - CONSELHO BRASILEIRO DE QUALIDADE DO LEITE.
Laboratórios|RBQL. 2020. Disponível em: https://cbql.com.br/. Acesso em: 05 jun. 2020.

EC - EUROPEAN COMMISSION. Corrigendum to Regulation (EC) No 853/2004 of the European Parliament and of the Council of 29 April 2004 laying down specific hygiene rules for food of animal origin. Official Journal of the European Union, L 226, p. 22-82, 2004. Disponível em: https://eur-lex.europa.eu/legal-content/EN/ TXT/?uri=CELEX\%3A32004R0853R(01). Acesso: 07 jun. 2020.

FAGUNDES, M. H. Uma nova etapa da Instrução Normativa ${ }^{\circ}$ 51: A região CentroSul. Revista de Política Agrícola, n. 2, p. 33-48, 2006.

FAO - FOOD AND AGRICULTURE ORGANIZATION OF THE UNITED NATIONS. Livestock Primary Data. Disponível em: http://www.fao.org/faostat/ en/\#data. Acesso em: 04 abr. 2020.

FDA - UNITED STATES FOOD AND DRUGS ADMINISTRATION. Grade “A" Pasteurized Milk Ordinance (2017 Revision). 2017. Disponível em: https://www. fda.gov/media/114169/download. Acesso: 07 jun. 2020.

FLORES-MIYAMOTO, A.; REIJ, M. W.; VELTHUIS, A. G. J. Do farm audits improve milk quality? Journal of Dairy Science, v. 97, n. 1, p. 1-9, 2014. DOI: 10.3168/ jds.2012-6228.

IBGE - INSTITUTO BRASILEIRO DE GEOGRAFIA E ESTATÍSTICA. Censo Agropecuário 2017. 2020a. Disponível em: https://www.ibge.gov.br/estatisticasnovoportal/economicas/agricultura-epecuaria/21814-2017-censo-agropecuario. html? $=\& \mathrm{t}=$ resultados. Acesso em: 04 abr. 2020 . 
IBGE - INSTITUTO BRASILEIRO DE Geografia E ESTATÍSTICA. Censo Agropecuário 2006 - Segunda apuração. 2020b. Disponível em: https://sidra.ibge.gov. br/tabela/1227. Acesso em: 04 abr. 2020.

LAMAS, J. M. N. et al. Qualidade da água utilizada na limpeza dos tanques de granelização de leite cru: Implantação e avaliação da cloração da água para garantia da qualidade do produto. Revista do Instituto de Laticínios Cândido Tostes, v. 70, n. 5, p. 239-252, 2015. DOI: 10.14295/2238-6416. v70i5.449.

LIMA, L. P. et al. Chilled raw milk quality: A case study in Zona da Mata region, Minas Gerais state. Ciência Rural, v. 50, n. 4, e20190749, 2020. DOI: 10.1590/0103$8478 \mathrm{cr} 20190749$.

MILANI, M. P. et al. Qualidade do leite em diferentes sistemas de produção, ano e estação climática. Revista Brasileira de Ciência Veterinária, v. 23, n. 3-4, p. 206-211, 2016. DOI: $10.4322 /$ rbcv.2016.058.

Milinski, C. C.; VEnTuRA, C. A. A. Os impactos do Programa Nacional de Melhoria da Qualidade do Leite - PNMQL na região de Franca-SP.

Revista Internacional Interdisciplinar INTERthesis, v. 7, n. 1, p. 170-198, 2010. DOI: $10.5007 / 1807-1384.2010 \mathrm{v} 7 \mathrm{n} 1 \mathrm{p} 170$.

NIGHTINGALE, C. et al. Influence of variable milk quality premiums on observed milk quality. Journal of Dairy Science, v. 91 , n. 3, p. 1236-1244, 2008. DOI: 10.3168/ jds.2007-0609.

OLIVEIRA, C. J. B. et al. Risk factors associated with selected indicators of milk quality in semiarid northeastern Brazil. Journal of Dairy Science, v. 94, n. 6, p. 31663175, 2011. DOI: $10.3168 /$ jds.2010-3471.

PANTOJA, J. C.; REINEMANN, D. J.; RUEGG, P. L. Associations among milk quality indicators in raw bulk milk. Journal of Dairy Science, v. 92, n. 10, p. 4978-4987, 2009. DOI: $10.3168 /$ jds.2009-2329.

PINTO, M. S. Contagem bacteriana total do leite cru produzido nos Estados do Paraná, São Paulo e Minas Gerais após implementação da Instrução Normativa $n^{0}$. 51/2002. 2008. 72 f. Dissertação (Mestrado em Medicina Veterinária) - Universidade Federal Fluminense, Niterói, 2008.

REZENDE, E. S. J. et al. Qualidade higiênicosanitária do leite cru em três mesorregiões de Minas Gerais. Revista do Instituto de Laticínios Cândido Tostes, v. 67 , n. 387 , p. 64-69, 2012. DOI: $10.5935 / 2238$ 6416.20120051 .

RIBAS, N. P. et al. Contagem bacteriana total em amostras de leite de tanque no estado do Paraná. Archives of Veterinary Science, v. 21 , n. 1, p. $32-43$, 2016. DOI: $10.5380 /$ avs. v21i1.41581.

SOUTO, L. I. M. et al. Qualidade higiênicosanitária do leite cru produzido em propriedades leiteiras do Estado de São Paulo, Brasil. Veterinária e Zootecnia, n. 3, v. 16, p. 491-499, 2009.

VELTHUIS, A. G. J.; VAN ASSELDONK, M. A. P. M. Process audits versus product quality monitoring of bulk milk. Journal of Dairy Science, v. 94, n. 1, p. 235-249. 2011. DOI: $10.3168 /$ jds.2010-3528 